\title{
The Effectiveness of Learning Freestyle Swimming Using the ISLAMT 2 E Based on Static Swimming Tools
}

\author{
Andarias Ginting ${ }^{1, *}$, Moch Asmawi ${ }^{1}$, James Tangkudung ${ }^{1}$, Raswin $^{2}$, Anggi Setia Lengkana ${ }^{3}$ \\ ${ }^{1}$ Sport Education Program, Post Graduate Program, Universitas Negeri Jakarta, Jakarta, Indonesia \\ ${ }^{2}$ Physical Education and Tourism, Sport Science Faculty, Universitas Negeri Medan, Medan, Indonesia \\ ${ }^{3}$ Physical Education of Elementary Teacher Program, Universitas Pendidikan Indonesia, Bandung, Indonesia
}

Received May 2, 2021; Revised June 25, 2021; Accepted July 19, 2021

\section{Cite This Paper in the following Citation Styles}

(a): [1] Andarias Ginting, Moch Asmawi, James Tangkudung, Raswin, Anggi Setia Lengkana, "The Effectiveness of Learning Freestyle Swimming Using the ISLAMT 2 E Based on Static Swimming Tools, "International Journal of Human Movement and Sports Sciences, Vol. 9, No. 5, pp. 863 - 875, 2021. DOI: 10.13189/saj.2021.090506.

(b): Andarias Ginting, Moch Asmawi, James Tangkudung, Raswin, Anggi Setia Lengkana (2021). The Effectiveness of Learning Freestyle Swimming Using the ISLAMT ${ }_{2}$ E Based on Static Swimming Tools. International Journal of Human Movement and Sports Sciences, 9(5), 863 - 875. DOI: 10.13189/saj.2021.090506.

Copyright $\odot 2021$ by authors, all rights reserved. Authors agree that this article remains permanently open access under the terms of the Creative Commons Attribution License 4.0 International License

\begin{abstract}
Quality teaching is inseparable from the learning strategies applied in delivering material in theory and practice. However, implementing learning strategies that will provide meaningful learning and a learning atmosphere for students is not an easy matter because students are unique individuals, different from one another, especially in their cognitive, affective, and psychomotor aspects. Based on this, lecturers must have sufficient initiative, knowledge, competence, and adequate conceptual power to implement an effective lecture strategy. This study aims to determine the effectiveness of learning freestyle swimming by using the $\operatorname{ISLAMT}_{2} \mathrm{E}$ learning strategy for students. This study used an experimental method with a randomized pretest-posttest control group. The research subjects were 40 people in the experimental group and 40 people in the control group. The conclusion of this study proves that learning to swim freestyle using the ISLAMT ${ }_{2} \mathrm{E}$ strategy on static swimming tools has been proven to be effective in improving students' swimming skills. The magnitude of the increase in students' swimming skills in the experimental group was seven people $(17.5 \%)$ in the low category, 33 people $(82.5 \%)$ had the moderate category, and $0 \%$ high category. In the control group, the increase in swimming in the low category was 31 people $(77.5 \%)$, nine people $(22.5 \%)$ in the moderate category, and the high category $0 \%$. This means that there are differences in learning outcomes of freestyle swimming skills between the experimental group and the control group.
\end{abstract}

Keywords Freestyle Swimming, Learning Strategies, $\mathrm{ISLAMT}_{2} \mathrm{E}$, Static Swimming Equipment

\section{Introduction}

As a facilitator, a teacher must be able to provide quality and meaningful teaching for his students. This job is not easy considering that students are unique individuals, differing from one another, especially in their cognitive, affective, and psychomotor abilities [1]. If you lecture and teach, you will learn how people respond to your instruction. What works for one person can not work for another because they interpret information differently, mainly while you are in the water [2]. Therefore, learning requires proper direction/instruction from the lecturer. Students' good understanding through learning, analyzing, and providing feedback on student performance results cannot be done optimally. Therefore, a proper learning strategy is needed to maximize effort [3], [4]. In learning freestyle swimming, students are given the same material (theory and practice) where the material is doable for some students, and for others, it is so difficult. Departing from the differences in student abilities, learning (lectures) must be carried out as effectively as possible to achieve the desired learning outcomes/objectives. Moreover, the learning effectiveness is also decided by choice of the learning media, as mention in [5]. 
The effectiveness of learning in freestyle swimming lectures can be adequately achieved. However, it is necessary to have an effort in learning stages that include theory and practice in its implementation. In the learning process of swimming so far, it is not practical to affect students' swimming outcomes/abilities. Many students are not very good at freestyle swimming with inadequate abilities (based on preliminary observations) because the assessment is subjective. It may happen because students do not master learning motion.

Further, the ratio of lecturers and students is not balanced, so that learning is ineffective. It results in students' affective, cognitive and psychomotor abilities differ each other. Moreover, conventional learning models are not effective if only used swimming boards. Learning does not show a clear strategy, and lecturers play a more role in the learning process. In connection with psychomotor, the cause of errors when doing freestyle swimming is the lack of movement skills and self-confidence in students [6].

Meanwhile, [7] stated that in some cases, There are noticeable errors in executing certain balance aspects of the crawl technique and some errors in the breathing technique. Further, [8], [9] believe that there are significant errors in the synchronization aspects of the crawl technique and a complete lack of breathing technique. Another thing in the form of inadequate practice lecture facilities also affects the quality and effectiveness of learning.

One of the efforts to overcome this problem is using the ISLAMT $_{2} \mathrm{E}$ learning strategy based on static swimming tools. ISLAMT ${ }_{2} \mathrm{E}$ combines several words, namely (Instruction, Saving, Learning, Analyzing, Measurement, Group Task, Independent Task, and Evaluation). ISLAMT $_{2} \mathrm{E}$ is a learning strategy used in the learning stages of freestyle swimming techniques. Meanwhile, static swimming is a tool used in learning swimming. All learning basic swimming techniques use this tool to be more effective. Activities are easy to observe, easy to provide feedback. ISLAMT $_{2} \mathrm{E}$ is a learning strategy applied to facilitate material delivery to students in stages until assessment and evaluation are more objective because there are test instruments.

Previous studies have been recorded regarding the performance of referees in a match. [10] found that verbal and visual feedback affect performance and learning freestyle swimming. Furthermore, [11] discovered that anthropometric variables, body composition, propulsion, and swimmer maturity influenced the $50 \mathrm{~m}$ freestyle swimming performance. However, previous studies have not yet led to the use of learning strategies with outstanding complexity. The static swimming-based ISLAMT $_{2} \mathrm{E}$ learning strategy is expected to increase the effectiveness of learning freestyle swimming so that meaningful and quality learning outcomes are achieved for students.

\section{Theoretical Framework}

\subsection{Swimming}

Swimming is an activity carried out in the water where the activity is different from everyday life carried out on land. Activities in water require special abilities in order to interact appropriately, especially in breathing. Swimming does not determine a specific limb movement pattern that must be done, meaning that it can use all the limbs at will so that they can move from one place to another. However, a combination of the motion of certain limbs regularly and continuously in water can be more efficient. [12] stated that swimming is a form of underwater mobility that uses a series of muscle actions to overcome gravity and move the body forward in the water. During a swimming stroke cycle, the subject's arms, legs, and trunk movements trigger changes in velocity. The arms and legs, and neck movements to take a breath during swimming are carried out regularly and continuously. The combination of these movements is grouped into four swimming styles [13]. There are freestyle, breaststroke, backstroke, and butterfly stroke. The four types of swimming styles are constantly taught and studied by all groups in swimming learning activities.

\subsection{Freestyle Swimming}

The fastest style of all styles in swimming is freestyle. Freestyle is also called front crawl [14]. The hallmark of freestyle is the rotating arm motion similar to the motion of an airplane propeller and the movement of the legs like a cross. Relating to freestyle swimming, [15] stated that freestyle is efficient and reliable. Freestyle swimming is as easy as walking for those who have mastered it. To that end, this stage aids in the development of the following abilities::

(a) Horizontal body line

(b) Rotation on a long axis

(c) High elbow catch

(d) Pressure on the water throughout the stroke

(e) Kicking rhythm

(f) Effective breathing

(g) Effective timing

You will be well on your way to mastering an effective freestyle stroke once you have mastered all of these skills [6]. Mastery of good skills can be obtained through learning and training efforts and assessing the techniques and factors that support swimming. The formation of swimming sports skills, in general, has a lot to do with the coordinated movements of the body components/organs. The coordination of body movements is influenced by nerve function and is obtained from learning and training results. Therefore, obtaining a high level of movement skills requires long-term training so that the function of the nervous system can be perfectly coordinated, leading 
to automation of motion. A good freestyle swimming technique will automatically not expend/drain excessive energy because the movement can be done efficiently. Freestyle swimming learning is related to movement techniques that must be studied and mastered well, including;

\section{a) Body Position}

The freestyle swimmer's body position is face down parallel to the water surface, relaxed and balanced. A good swimmer will be able to keep his body position in line with the water surface during his swimming distance. Streamline the process. Its goal is to help you get into a good swimming position and reduce the drag force that slows you down and makes each movement more difficult. You will learn more about streamlining; for now, here are some drills to help you get started [16].

\section{b) Floating Kick}

The primary function of the legs is as a stabilizer (regulator of body balance) and as a driving force/mover to keep the body in a streamlined state so that the prisoner becomes small. An effective leg movement can aid in maintaining a horizontal body posture, balancing arm action, and providing varying degrees of propulsion [17]. Flutter kicking or foot stroke rhythm there are several types as a guideline;

a The six-beat kick with one arm cycle.

b The four-beat kick with one arm cycle.

c The two-beat kick with one arm cycle.

When doing the movement, the legs/feet are under the water surface when they rise and fall between $25-30 \mathrm{~cm}$. The coordination styles used by world-class swimmers vary greatly. Some people, especially sprinters, use the traditional six-beat stroke. Others, especially distance swimmers, tend to use a four- or two-beat stroke, with the kick appearing to be used only for balance [15]. In freestyle swimming, the rhythm of the foot strokes will determine the efficiency of foot movement, so it must be noted that alternating leg kicks will provide a constant boost to the forward swimming pace.

\section{c) Breathing}

How to breathe on land and in water during swimming is different. The air is inhaled using the nose on land, and it is natural while in the pool. When swimming freestyle, the air is inhaled using the mouth, and this is unusual, and this must be learned to get used to it. [18] stated that from a beginner's perspective, the two most critical elements of swimming breathing are getting familiar with swimming, your face is in the sea, and your breathing has a pattern.

Breathing techniques when swimming freestyle can be done in several ways, as Corlett (1980) suggested: other terms used in connection with breathing. Breathing holding; the breath is held during several stroke cycles, Uni-lateral; breathing on one side only, Bi-lateral; a term used in front crawl, where breathing takes place on alternate sides every $11 / 2$ cycles.

Inhaling should be done as effectively as possible not to affect the work of other limbs such as the arms and minimize obstacles that occur in the body's forward motion. It also should be done by turning your head when swimming freestyle, not lifting. The location of a swimmer's head in freestyle is essential, particularly when the swimmer is breathing. When you tilt your head to the left to breathe, it should be at a 90-degree angle, so only one eye and the majority of your mouth are out of the water [19]. Moreover, [13] stated that many swimmers recover their arms higher on the breathing side and swing them lower and more lateral on the non-breathing side. It causes their body to roll more than 45 degrees against the breathing side rather than the non-breathing side.

\section{d) Hand Rotation}

The arm is an upper limb that plays an essential role in freestyle swimming. In addition to technique, strength, and power, the length of the arm's reach in the future with a reasonable degree of shoulder joint flexibility is also significant. Important associations between arm length, frontal hand area, body shape and height, and swimming ability have been shown in this regard. [20].

Movement or stroke of the arm is a significant component in freestyle swimming in bringing the body forward on the water surface, the faster and more frequent strokes of the arm, the faster the body forward will be. Reference [21] argued that the front crawl stroke is characterized by a cyclical pattern of arm rotation and a flutter kicking motion with the legs. The arm stroke produces the bulk of momentum, but the legs have also contributed to travel speed. Previous research has shown that the arm stroke provides $90 \%$ of the overall propulsive thrust in sprint freestyle. [22]. Meanwhile, [16] believed that it is widely agreed that in competitive swimmers, the arm stroke accounts for nearly $90 \%$ of overall swimming velocity during maximum front-crawl swimming. Arm stroke is an essential indicator in freestyle swimming, so it is necessary to master the arm stroke technique by analyzing its technique. Five aspects of competence were examined qualitatively: $1=$ hand entry (extend the arm straight ahead from the shoulder and position it in the water in front of the head), 2 = palm on the side (the palm should face the bottom of the pool with the thumb marginally higher than the fingertips and the elbow higher than the wrist on the side); $3=$ breathing (the head should be cocked forward about 45 degrees); $4=$ rebound (the elbow should be high and above the hand in the pushing phase of the stroke, just as it is in the recovery phase); $5=$ catch and pull over (catch the water and begin an underwater pull) [10]. Furthermore, the rotational stages of the freestyle arm stroke consist of several phases: entry phase, catch phase, pull phase, push phase, release Phase, recovery phase. 
Understanding the rotational stages of the arm is also significantly related to the pattern of movement of the arm itself when in the water. For example, the arm movement pattern used by freestyle swimmers is the $\mathrm{S}$ movement pattern, which affects swimming skills. Alternatively, better known as the S-Shaped arm path movement pattern [23].

\section{e) Freestyle Swimming Coordination Movement}

The coordination movement is the right time to coordinate all phases of the freestyle swimming techniques that have been mastered, starting from gliding, stroke/leg movement, arm stroke movement, and breathing movements properly. Coordination is the ability to quickly and efficiently perform movements with varying degrees of difficulty and complete accuracy [24]. After this coordination, it will then produce a particular skill movement. The purpose of coordinating is to form a complete unity of motion from several components of the limb movement smoothly without intermittent work called freestyle swimming skills. Skill movement follows a particular pattern or shape that requires coordination and control of part or all of the body, which can be done through the learning process. A person who can perform skill movements well is skilled [25]. The coordination movement is said to be good if, between the legs, arms, and breath movements, there is synchronization in a constant rhythm to produce a smooth-running power. States that putting all of these individual skills together is the last part of the process. How all the movements of this skill can be done perfectly must be supported by the components of the movement consisting of energy, muscle contraction, nerves, bones, and joints that function properly [26].

\subsection{ISLAMT 2 E Learning Strategies}

The basics of learning include three things: open the lecture; explain the material; inspire, motivate, facilitate students to listen, read, discuss, question, develop, and so on so that students master the material given and the last; close the lecture. Students who only listen to lecturers lecture, read books, watch videos, and do demonstrations, mastery of the material is only $30 \%$, but if students learn the material by discussing, practicing, and teaching it to others, the mastery of the material can reach $90 \%$ [27]. In its implementation, the main essence of the basis of learning is the strategy used in the learning itself, how all the aspects contained therein can be carried out as best as possible. ISLAMT $2 \mathrm{E}$ learning strategy is one of the applied learning strategies. This learning strategy is not the name of a religion but is no more than naming a learning strategy in the form of stages of learning. The components of this learning strategy consist of five main components and three supporting components;

a The Core Components;

$$
\mathrm{I}=\text { Instructing }
$$

Lecturers instruct students directly to write about practical material to identify all students' perceptions during lectures.

$$
\mathrm{S}=\text { Saving }
$$

Students keep and process all instructions in their mind/memory to follow the course well.

$$
\mathrm{L}=\text { Learning }
$$

Students learn swimming theory from lecturers' explanations, reading books or modules, watching videos, discussing, especially learning to practice swimming techniques with demonstrations and peer tutors.

$$
\mathrm{A}=\text { Analysing }
$$

Lecturers analyze the theory and practice errors of the freestyle swimming technique demonstrated by students in the learning process, identify learning weaknesses, and improve.

$$
\mathrm{M}=\text { Measurement }
$$

Lecturers take measurements and gradual assessments of the theory and practice of freestyle swimming techniques to know how students have mastered freestyle swimming's fundamental theories and techniques during the lecture process.

\section{b Supporting Components:}

$$
\mathrm{T}_{1}=\text { Group Tasks }
$$

Lecturers give group assignments to improve student knowledge and skills due to information-sharing interactions among group members (discussion and peer tutoring). Bills in this group assignment are reports in papers and documentation of activities carried out.

$$
\mathrm{T}_{2}=\text { Individual Tasks }
$$

Lecturers give independent assignments to each student to improve their theoretical knowledge and skills outside lecture hours by exploring learning resources as widely as possible. The assignment is a paper report with documentation.

$$
\mathrm{E}=\text { Evaluation }
$$

The lecturer conducts an overall evaluation and assessment of each student to determine the extent of his learning achievement, followed by deciding whether the student deserves to pass with grades A, B, C, or failed.

To be more precise about how the flow of freestyle swimming learning using the ISLAMT $_{2} \mathrm{E}$ approach based on static swimming tools, can be seen in Figure 1: 


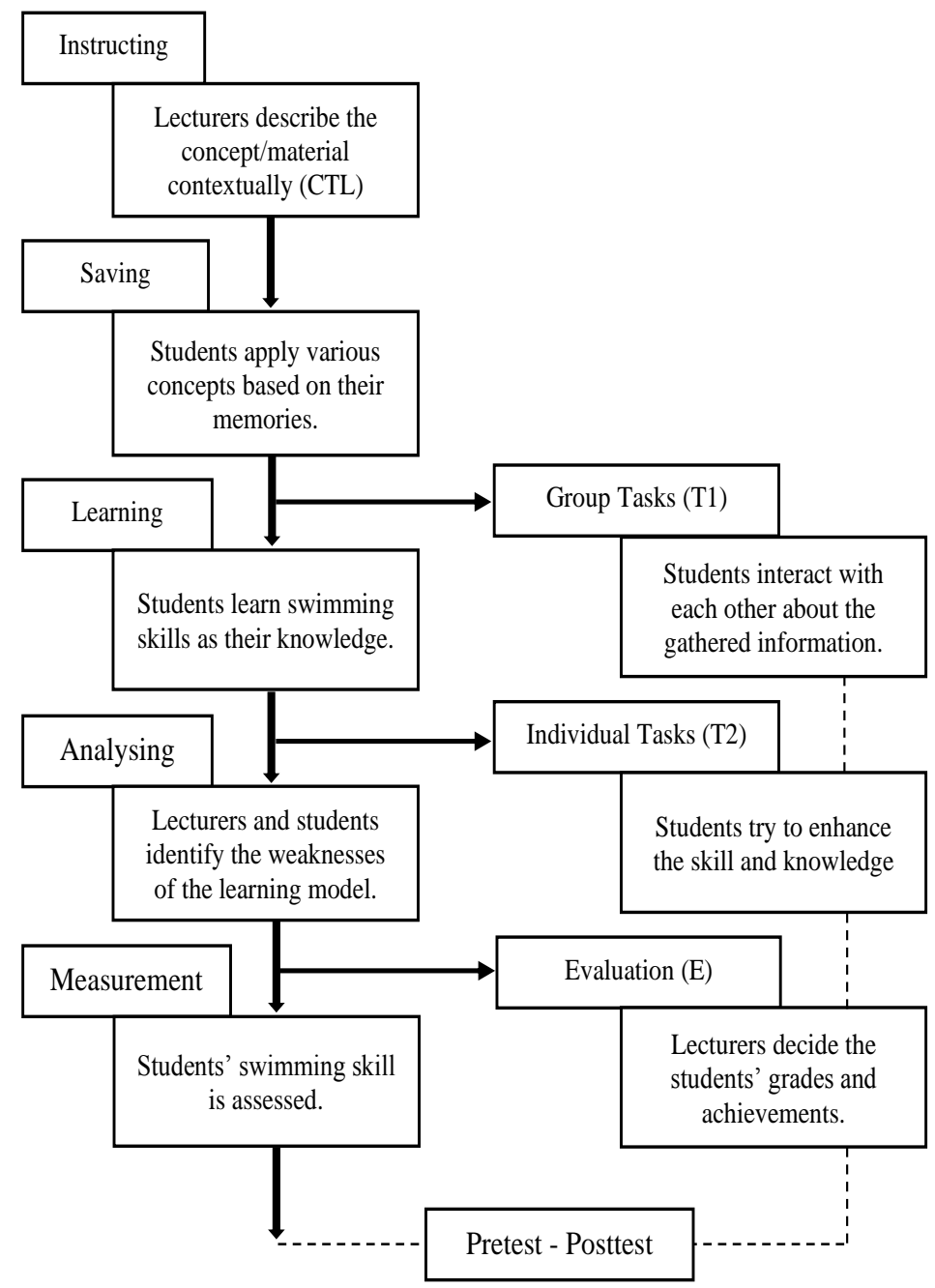

Figure 1. ISLAMT ${ }_{2}$ E learning strategies

The advantages of this learning strategy based on Figure are that students can learn to listen/listen to material well, work together on joint assignments, provide and receive constructive feedback, respect differences of opinion, support other opinions with evidence, and respect diverse perspectives. This learning strategy can also bring students to real situations in learning simulated in peer tutor practice to gain general and specific experiences empirically through direct practice in improving their skills.

\subsection{Static Swimming}

Static swimming is a term that is rarely found in Indonesia, especially in the learning process. This term refers to a tool used to learn to swim. The static swimming tool is in the form of a strong post made of flexible fiber where one end is attached to a rope using a carabiner, and the other end of the rope is attached to a belt attached to the waist of the role. Swimmers can swim by not moving places, but that does not diminish the true meaning of swimming because the swimming technique movements can be carried out in the same way as the actual freestyle swimming motion. [28] believed that a swim tether keeps you in one spot in the water, allowing you to swim and swim and swim. You're not going to go anywhere. Static swimming is almost the same as tethered swimming. Reference [29] stated that tethered swimming is accomplished by connecting a swimmer to an inelastic rope, with the other end attached to a load cell mounted on the pool's end wall. This method entails muscle activity patterns that are somewhat close to those used in free-swimming. For more details on how the tools and use of static swimming can be seen in Figure 2.

The use of static swimming tools, as in figure 2, allows participants to have the opportunity to learn and improve swimming skills, not just to fixate on freestyle swimming. Following are the general benefits of exercising using a static swimming device:

a) Increased sensor capacity; Static swim equipment works on sensory perception - nerve endings located in muscles, tendons, and joints that transmit information to the central nervous system that controls the body. 
b) Increased self-awareness; Static swim increases a person's self-awareness of position, movement, and balance through training. Be more aware of the special effects of the various movements of the body parts underwater.

c) Increased awareness of neural control; being aware of how the body works can better evaluate the efficiency and consequences of each movement or even improve existing techniques.

d) Movement coordination; Static swimming allows swimmers to coordinate movements better while being more aware of inner sensations and less dependent on external stimuli.
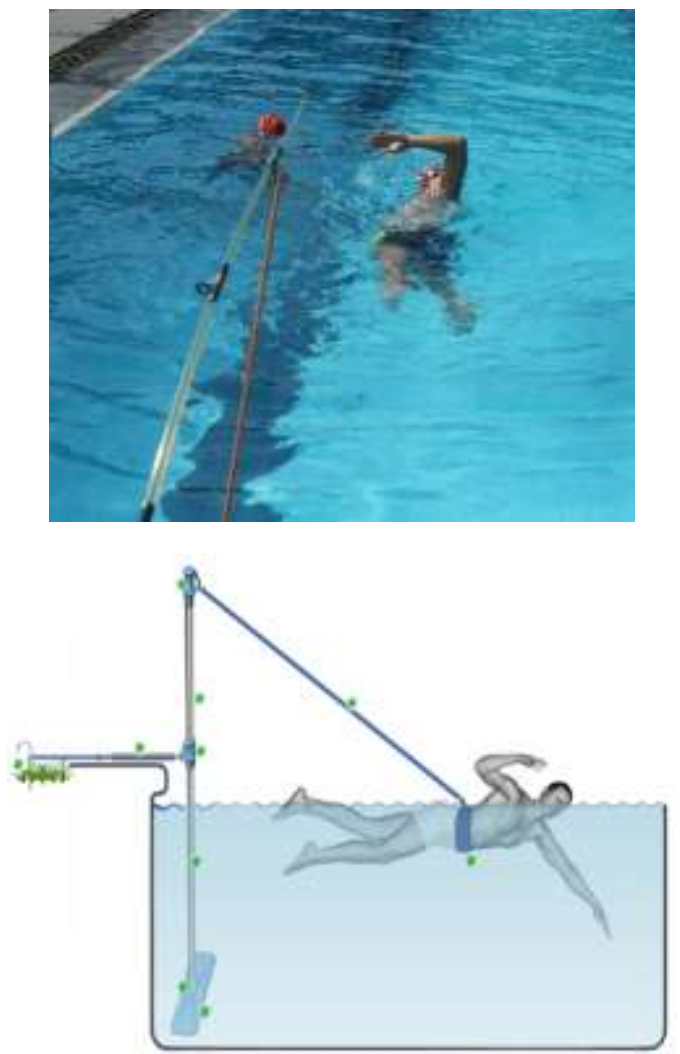

Figure 2. Static swimming

\section{Materials and Methods}

\subsection{Research Design}

The research methodology used an experimental research approach to determine the effectiveness of learning swimming with a randomized pretest-posttest control group design. Experimental research tries to make something happen to the dependent variable through a series of treatments for the independent and dependent variables. In this study, there is a moderator variable; cognitive ability. Therefore, the design used is factorial. It is a modification of the "pretest-posttest control group design." It is suitable for use in the author's research because it has two independent variables and two moderator variables. Therefore this design is referred to as a "two by two factorial design."

The participants in this study were all 140 students of sports coaching education in the sports science faculty of Medan State University. Due to limited time, cost, and energy, researchers used probability sampling techniques or simple random sampling to determine the sample. This method is done when the members of the population are homogeneous. Simple random sampling was done by lottery, selecting numbers from a random number list [30]. With this technique, 80 samples were chosen. The samples were divided into two groups by lottery so that 40 samples in experimental groups were given swimming exercises based on static swimming tools, and 40 samples in control groups were given conventional freestyle swimming exercises.

\subsection{Procedures}

The first step was to make observations in swimming lectures, then identify new students' freestyle swimming ability for three meetings. It was because the number of students reached 140 people. Before later, 80 people were randomly taken. To make it easier to do the test and treatment, it is divided into several sessions, consisting of 6 people. It is because there are only six passes in the pool. The preliminary test and the final test were carried out to obtain data on the participants' ability before being given treatment and after being given treatment. The 50-meter swimming test was not assessed based on the participants 'freestyle swimming speed but instead assessed the extent of the participants' freestyle swimming movement technique. This test is given the opportunity only once in each test, both the initial test and the final test.

\subsection{Research Instrument}

The data obtained in this study are the measurement results of the freestyle swimming test. The instrument used was a 50-meter freestyle swimming test adapted from [31] and the Freestyle Swimming Assessment Rubric that has been compiled by the author based on the reference of the stages of freestyle swimming motion.

This applied assessment model provides the opportunity to form an objective assessment of acquired swimming skills for the participants. The objective assessment prevents negative results from interpersonal relationships in participant swimming training. Therefore, the assessment approach is objective, so an assessment rubric is needed as a benchmark for scoring each participant. Through the results of this assessment, an evaluation is carried out to determine the suitability and effectiveness of the instrument. Evaluation is carried out based on an assessment instrument/rubric prepared to obtain the required data. 
The first step when conducting an assessment using this rubric is to divide the number of observers according to the number of movement skill stages. One observer cannot do it alone because participants cannot carry out each stage of the freestyle swimming movement one by one; all stages of the movement must be carried out continuously, from one movement stage to another. Therefore, because the stages of movement skills in this rubric are five stages, five observers are, of course, equipped with knowledge and uniformity when assessing. This method will make it easier for the observer to assess the movement ability of the participants well.

In this case, after the instrument has been constructed, the aspects measured based on theory, then the expert will be consulted. Experts were asked for their opinion about the instrument, the possibility of the instrument can be used without revision, need small revision, and maybe a complete revision. The number of experts used as many as three people following the scope of research. After the construct testing from the experts was completed, then the instrument testing was continued. To obtain or prove a reliable test instrument, the instrument that the experts have approved is tested on subjects outside of the learning model trial group. It is done so that a reliable instrument is obtained, meaning that the instrument is good enough to reveal reliable data.

Furthermore, based on the product-moment correlation test results, the r-obtained result is 0.83 with a high positive correlation interpretation. While the critical value of $r$ table with the number of respondents $n=27$, the result is 0.381 (r-obtained $=0.83>$ r-table $=0.381$. For the Instrument reliability test, by looking at Cronbach's Alpha value of 0.466 , it can be stated that the style swimming test instrument-free is declared reliable. Thus, the test instrument compiled can be used

The independent variable in this study is the freestyle swimming variable using an instrument that refers to the primary motion stages of swimming from [32], which was later developed by the author, including body position, leg movements, arm movements, breathing, coordination movements (perfect swimming). Table 1 presents a grid from the scoring rubric used to measure the participants' freestyle swimming technique skills:

Table 1. Freestyle Swimming Assessment Rubric

\begin{tabular}{|c|c|}
\hline Movement Skills & Indicators \\
\hline \multirow{4}{*}{ Body Position } & Streamlined body position. The body, when sliding straight \\
\hline & Head position. The head is parallel to the arms straight ahead, and the view to the front-floor \\
\hline & The body makes a forward slide (acceleration) \\
\hline & Legs and arms are straight in line with the body (waist does not twist) \\
\hline \multirow{4}{*}{ Legs movements } & The steady kicking rhythm does not change \\
\hline & The distance between the right and left legs when doing the movement is between $15-30 \mathrm{~cm}$ \\
\hline & Axis movement of the leg from the groin, the knee is slightly bent as the beginning of the toe tip \\
\hline & The feet are below the water level $(20-30 \mathrm{~cm})$ \\
\hline \multirow{4}{*}{ Hands movements } & $\begin{array}{l}\text { I am entering the tips of the fingers into the water surface (entry) with the thumbs first, followed by the } \\
\text { arms. }\end{array}$ \\
\hline & The phases of catching water and pulling the arms form an unchanging motion pattern \\
\hline & $\begin{array}{l}\text { Push phase by extending the arms behind the sides of the body as the end of the arm movement in the } \\
\text { water. }\end{array}$ \\
\hline & $\begin{array}{l}\text { In the resting phase (recovery phase), the elbow is bent for efficient arm motion by raising the arm above } \\
\text { the water's surface. }\end{array}$ \\
\hline \multirow{4}{*}{ Respiration } & The position of the head is slightly down when in the water \\
\hline & The appearance of the breath is carried out only to the right or to the left \\
\hline & The position of the head tilted following the body to the side, and the mouth takes the breath \\
\hline & You can see air bubbles when you exhale underwater through your nose and mouth. \\
\hline \multirow{4}{*}{$\begin{array}{l}\text { Movement coordination } \\
\text { (perfect swimming) }\end{array}$} & Coordination of kicking legs and stroking arms with a constant rhythm (2,4 or 6 kicks per arm stroke) \\
\hline & Coordination of arm strokes and constant breathing (right arm strokes to the right and vice versa) \\
\hline & Leg-breath-arm coordination. (leg pluck, arm stroke, and exhalation) in a steady rhythm. \\
\hline & Freestyle swimming normally as far as 50 meters. \\
\hline
\end{tabular}




\section{Result}

\subsection{Data Normality Test}

The data obtained during the study were then analyzed using a statistical approach. The first statistical testing stage in this study was the normality test using Kolmogorov Smirnov with the help of the SPSS for Windows 19 series application program. Data for the normality test can be seen in table 2 :

Table 2. Normality Test

\begin{tabular}{|c|c|c|}
\hline Variable & Statistic Score & Significance \\
\hline Experiment group & 1,278 & 0,072 \\
\hline Control group & 1,191 & 0,069 \\
\hline
\end{tabular}

Based on the table data, it shows that the Kolmogorov-Smirnov $\mathrm{Z}$ test results with the Asymp.Sig (2-Tailed) value ranging from 0.069 to 0.072 . Because both groups have a symp sig greater than 0.05 , the data in this study are normally distributed, so it is feasible to carry out further analysis using parametric statistics.

\subsection{Homogeneity Test}

The next test step is the homogeneity test of the data. This testing stage is a step to determine whether the data come from a homogeneous population or not. In addition, the homogeneity test is also carried out as a continuation of the data normality test, namely to determine the next step regarding the type of statistical method used, whether parametric or non-parametric. Because the absolute requirement of the parametric statistical test is that the data to be tested must be normal and homogeneous. The following summarizes the results of the static swimming-based freestyle swimming homogeneity test in each group is presented in table 3 .

The homogeneity test was carried out by comparing the freestyle swimming skills between the experimental and control groups. Based on the data served in table 3, the average obtained is 1.960 with a probability value (Sig.) Of 0.167. Meanwhile, based on the mean value, the result is 1.982 , and the probability value (Sig.) 0.165 . The probability value (Sig.) is based on the mean value and the mean value $>0.05$. Thus it can be concluded that the data come from a population that has the same variance. In other words, the data are homogeneous.

\subsection{Results of Hypothesis Testing using ANOVA}

If the data are normal and homogeneous, then the next step is a significance test to find out the proposed hypothesis. The research hypothesis was tested using mixed factorial ANOVA analysis using SPSS Series 19 with the main components: (1) ANOVA; (2) Multiple Comparisons. The results can be seen in Table 4 .

Table 3. Homogeneity Test Result

\begin{tabular}{|c|c|c|c|c|c|}
\hline & & Levene Statistic & df1 & df2 & Sig. \\
\hline \multirow{4}{*}{$\begin{array}{c}\text { Freestyle Swimming } \\
\text { Tool-Based Static } \\
\text { Swimming }\end{array}$} & Based on Mean & 1.960 & 1 & 78 & .167 \\
\cline { 2 - 7 } & Based on Median & 1.982 & 1 & 78 & .165 \\
\cline { 2 - 7 } & Based on Median and with adjusted df & 1.982 & 1 & 56.480 & .165 \\
\cline { 2 - 6 } & Based on trimmed mean & 1.949 & 1 & 78 & .168 \\
\hline
\end{tabular}

Table 4. Hypothesis Testing "Tests of Between-Subjects Effects"

\begin{tabular}{|c|c|c|c|c|c|}
\hline \multicolumn{7}{|c|}{ Dependent Variable: ISLAMT 2 E \& conventional } \\
\hline Source & Type I Sum of Squares & df & Mean Square & F & Sig. \\
\hline Model & $4615.500^{\mathrm{a}}$ & 4 & 1320.540 & 262.175 & .000 \\
\hline$X$ & 4313.322 & 2 & 1601.106 & 611.316 & .000 \\
\hline$Y$ & 201.056 & 5 & 140.072 & 35.530 & .000 \\
\hline$X^{*} \Upsilon$ & 160.006 & 5 & 160.006 & & .000 \\
\hline Error & 103.022 & 64 & 2.534 & & \\
\hline Total & 4840.000 & 80 & & & \\
\hline
\end{tabular}


As presented in Table 4, the analysis results show that the entire value of the Sig coefficient for each group is $<0.05$. So this study shows that there are differences in the results of swimming skills before and after treatment. It proves that learning to swim freestyle using the ISLAMT $_{2} \mathrm{E}$ learning strategy based on static swimming has improved students' swimming skills. Furthermore, determining the magnitude of the increase in swimming skills of each student is done by determining the normalized g-score [33] as in Table 5 and can be determined for each category through the following procedures;

Table 5. N-Gain Category

\begin{tabular}{|c|c|}
\hline Normalized Gain Range & Category \\
\hline$(<\mathrm{g}>)<0,30$ & Low \\
\hline $0,70>(<\mathrm{g}>) \geq 0,30$ & Medium \\
\hline$(<\mathrm{g}>) \geq 0,70$ & High \\
\hline
\end{tabular}

In table 6 , it can be seen that the categories of student swimming skills improvement are; 7 people or $17.5 \%$ in the low category, 33 people or $82.5 \%$ in the medium category, and $0 \%$ in the high category. Then in table 6 presents the data to test the increasing freestyle swimming skills in the control group. The table shows the increase in swimming skills of the control group students: 31 people or $77.5 \%$ in the low category, nine people or $22.5 \%$ in the medium category, and $0 \%$ in the high category. The experimental group and the control group were tested using the Mann-Whitney $U$ test technique. The results of data analysis obtained $Z_{\text {obtained }}$ value $=2.47$. To determine the $\mathrm{Z}_{\text {table }}$ value with two-group test $\alpha / 2=0.05 / 2=0.025$.
The area of the curve $\mathrm{F}(\mathrm{z})=0.5-0.025=0.4750$. Thus the coordinate $\mathrm{Z}$ table $=1.96$.

Table 6. The category of students' swimming skills improvement in the experimental and control group

\begin{tabular}{|c|c|c|}
\hline \multicolumn{3}{|c|}{ Experimental Group } \\
\hline Category & $\mathbf{n}$ & $\%$ \\
\hline The number of categories is low & 7 & $\begin{array}{c}17,5 \\
\%\end{array}$ \\
\hline The number of categories is medium & 33 & $\begin{array}{c}82,5 \\
\%\end{array}$ \\
\hline Control Group & 0 & - \\
\hline Category & $\mathbf{n}$ & $\%$ \\
\hline The number of categories is low & 31 & $\begin{array}{c}77,5 \\
\%\end{array}$ \\
\hline The number of categories is medium & 9 & $\begin{array}{c}22,5 \\
\%\end{array}$ \\
\hline Number of high categories & 0 & - \\
\hline
\end{tabular}

Because the value of $Z_{\text {obtained }}=2.47>Z_{\text {tabel }}=1.96$ and it is in the area of rejection of Ho, then Ha is accepted. This means that there are differences in learning outcomes of freestyle swimming skills between the experimental group and the control group. The experimental group with different mean post-test and pre-test $(77.80-62.72)=$ 15.08 , the increase was better than the control group with the mean difference between post-test and pre-test (71.40 $-64.43)=6,97$

The general significance test was carried out to determine the significance per pair based on: (a) learning strategies and (b) cognitive abilities. To see significantly different pairs, see the Multiple Comparison in Table 7.

Table 7. Multiple Comparisons Significance Test

\begin{tabular}{|c|c|c|c|c|c|c|c|}
\hline & \multirow[b]{2}{*}{ (I) Learning Strategy } & \multirow[b]{2}{*}{ (J) Learning Strategy } & \multirow{2}{*}{$\begin{array}{c}\text { Mean Difference } \\
\text { (I-J) }\end{array}$} & \multirow{2}{*}{$\begin{array}{l}\text { Std. } \\
\text { Error }\end{array}$} & \multirow[b]{2}{*}{ Sig. } & \multicolumn{2}{|c|}{ 95\% Confidence Interval } \\
\hline & & & & & & $\begin{array}{l}\text { Lower } \\
\text { Bound }\end{array}$ & Upper Bound \\
\hline \multirow{12}{*}{ Tukey HSD } & \multirow{3}{*}{ ISLAMT $_{2} \mathrm{E}$ (High) } & $\operatorname{ISLAMT}_{2} \mathrm{E}$ (Low) & $3.42^{*}$ & .697 & .003 & .52 & 2.43 \\
\hline & & Conventional (high) & $4.62^{*}$ & .697 & .001 & 3.51 & 7.26 \\
\hline & & Conventional (low) & $5.48^{*}$ & .697 & .002 & .64 & 3.23 \\
\hline & \multirow{3}{*}{ ISLAMT $_{2} \mathrm{E}$ (Low) } & ISLAMT $_{2} \mathrm{E}$ (high) & $-1.62^{*}$ & .697 & .004 & -3.35 & -.53 \\
\hline & & Conventional (high) & $3.07^{*}$ & .697 & .000 & 1.03 & 3.73 \\
\hline & & Conventional (low) & .00 & .697 & .001 & -2.32 & 2.60 \\
\hline & \multirow{3}{*}{ Conventional (high) } & ISLAMT $_{2} \mathrm{E}$ (high) & $-5.87^{*}$ & .697 & .000 & -6.35 & -3.57 \\
\hline & & ISLAMT $_{2} \mathrm{E}$ (low) & $-3.20^{*}$ & .697 & .001 & -5.63 & -3.26 \\
\hline & & conventional (low) & $-3.30^{*}$ & .697 & .000 & -3.40 & -4.23 \\
\hline & \multirow{3}{*}{ Conventional (low) } & ISLAMT $_{2} \mathrm{E}$ (high) & $-5.32^{*}$ & .697 & .001 & -4.08 & -.53 \\
\hline & & ISLAMT $_{2} \mathrm{E}$ (low) & .00 & .697 & .000 & -2.42 & 3.64 \\
\hline & & conventional (low) & $2.03^{*}$ & .697 & .002 & 4.32 & 4.56 \\
\hline
\end{tabular}


Based on the analysis of variance calculation and the Tukey test above, the two-factor analysis of the difference between the effectiveness of ISLAMT ${ }_{2} \mathrm{E}$ learning and the conventional model as a whole is as shown in table 4 (Tests of Between-Subject Effect), showing Fobtained = $262.175>$ Ftable $=2.56$. It means that learning using $\mathrm{ISLAMT}_{2} \mathrm{E}$ learning (average increase of 11.16) is significantly better than conventional learning (average increase of 8.23) towards improving students' overall freestyle swimming skills.

The results of the Tukey test calculation on between the effectiveness of ISLAMT ${ }_{2} \mathrm{E}$ learning and the conventional model for groups of students who have high cognitive abilities are shown in table 7 (Multiple Comparison). It shows that learning using ISLAMT $_{2} \mathrm{E}$ learning (average increase of 12.49) is significantly better for groups of students who have high cognitive abilities than conventional models (average increase of 6.34) towards improving students' freestyle swimming skills as a whole.

\section{Discussion}

Strategy is a decision to act from educators using available skills and educational resources to achieve goals through effective relationships between the environment and the most favorable conditions. Learning strategies relate to the way educators choose to improve learning materials in a particular learning environment [34]. The choice of ISLAMT ${ }_{2} E$ learning strategies is not determined by chance but is based on certain considerations such as learning objectives, characteristics of students, resources and facilities, characteristics of presentation techniques. Therefore, an effective teaching and learning process requires appropriate strategies, methods, and learning media, especially in swimming lessons, especially in freestyle swimming. In students' learning process, educators need to develop teaching strategies that include using various learning methods and learning experiences that are expected to be experienced by students [35].

In a good learning process, two-way interaction is needed; learning resources from the teacher and students also become subjects of knowledge; therefore, in the learning process, cognitive abilities greatly affect the learning process [36], especially when the learning model used is not the usual model, more understanding is needed to follow the process well.

Cognitive ability is a person's ability to think, make choices, solve problems so that he can choose and determine which path is the best, what attitude is appropriate, and others he faces in life [37]. There are several things related to cognitive abilities, including (a) high cognitive abilities can be obtained by birth, meaning that a person from birth already has cognitive abilities that exceed the average person in general; (b) high cognitive abilities can also be obtained through the process of learning and practice. Cognitive ability is what distinguishes one individual from another [38]-[40].

Learning to swim is related to mastery of movement skills and is very identical with speed [41]. At the same time, speed is essential in freestyle swimming to complete a swimming distance as quickly as possible. Swimming speed is influenced by drag as the main factor [42]. Swimming speed depends on the interaction between two forces: one is generated to propel the swimmer forward, while the other acts in a direction that prevents propulsion. Furthermore, [43] swimming speed depends on the balance between thrust and active resistance. When the active resistance becomes more significant than the thrust in swimming, the swimmer's speed will decrease. Therefore reducing active resistance is essential to obtain maximum speed. The active obstacle here is meant to be caused by excessive bending of the leg and the arm's stroke in the water. Active resistance of WS: whole stroke and AS: arm stroke as estimated using the MRT method: measured values of residual thrush show a higher resistance value than passive resistance with SP: streamlined position [44]. Streamline the goal is to maintain a good swimming position and minimize drag forces that slow you down and make it more challenging to make each movement. The body's position parallel to the water surface is very efficient in building the effectiveness and speed of swimming. It is clear from this result that the active resistance in freestyle swimming is greater than the passive resistance, regardless of the use of foot kicks [45].

The main inhibiting factor for swimmers to swim faster is the water resistance itself. This water resistance depletes the swimmer's energy, causing the swimmer to exert more effort to swim than to run. The leading causes of water resistance are water flow patterns, including turbulence, watering due to movement of the hands and feet, waves, and friction of the body surface (skin) /clothing. To reduce water resistance (turbulence), a swimmer will swim with the body as flat as possible with the water surface, but this method can reduce forward movement because the hand is not too free to move, if the hand is free to move, it will cause turbulence, this can be overcome by improving the pattern technique. Movement/stroke of the arm in the water while swimming, and rotating the body up to $90^{\circ}$ to the surface of the water while taking a breath and holding the arm forward [46].

The concept of using a static swimming device is that the swimmer here does not experience significant displacement, but it does not reduce the true meaning of swimming because the swimming movements that are carried out are the same as the natural freestyle swimming movement. Swimmers learn Techniques and learn how to reduce drag while swimming. This approach involves a pattern of muscle activation that is very similar to that observed in free-swimming. In addition, [47] use a swimming mooring such as a static swim more secures the swimmers in one pool to swim by learning the swimming 
movement techniques. Learning to swim freestyle is an attempt to master the movement techniques needed. The movement techniques must be taught and must be well mastered. Swimming is a very technique-oriented sport. The best swimmers are better efficient in forwarding speed motion over a certain distance in the water environment [48]. [49] explained that ineffective body movement with forwarding motion leads to a waste of energy associated with the body swaying up and down at an ideal trajectory, with predictable adverse consequences for swimming ability.

For learning opportunities and skills improvement, the static swim is helpful; (1) Increased sensor capacity; The dynamic resistance of the static swimmer increases the volume of water that the swimmer has to move forward theoretically. Due to this, swimming speed is reduced, and underwater strength is increased. Static swim equipment works on sensory perception - nerve endings located in muscles, tendons, and joints that transmit information to the central nervous system that controls the body. (2) Increased self-awareness; static swim increases a swimmer's self-awareness by subtly providing information about the position, movement technique, and balance through training. (3) Increased awareness of neural control; Becoming more aware of how the body works, a swimmer can better evaluate the efficiency and consequences of each movement. Swimmers can discover new techniques using only muscles not previously involved (beneficial, especially in the slide stroke phase when the drag is at maximum extension) or even improve existing techniques. (4) Coordination of movements; static swim allows the swimmer to coordinate movement better and at the same time be more aware of inner sensations and less dependent on external stimuli. The combination of learning aids in a series of static swim tools can create a better learning atmosphere in achieving goals.

\section{Conclusions}

The conclusion of this study proves that learning to swim freestyle using the ISLAMT $_{2} \mathrm{E}$ learning strategy based on static swimming tools has been proven to be effective in improving students' swimming skills. The magnitude of the increase in students' swimming skills in the experimental group was that seven people $(17.5 \%)$ had a low category, 33 people $(82.5 \%)$ had a moderate category, and $0 \%$ high category. In the control group, the increase in swimming in the low category was 31 people $(77.5 \%)$, nine people $(22.5 \%)$ in moderate, and the high category $0 \%$. The test of the two independent means of the experimental group and the control group obtained $\mathrm{Z}_{\text {obtained }} 2.47$, and this result was compared with the $\mathrm{Z}$ table. To determine the Ztable with two-party test $\alpha / 2=$ $0.05 / 2=0.025$. The area of the curve $F(z)=0.5-0.025$ $=0.4750$. Thus the coordinate $\mathrm{Z}$ table $=1.96$. Because the value of $\mathrm{Z}_{\mathrm{Obtained}}$ is $2.47>\mathrm{Ztable} 1.96$, it means that $\mathrm{Ho}$ is rejected, or $\mathrm{Ha}$ is accepted. This means that there are differences in learning outcomes of freestyle swimming skills between the experimental group and the control group. The experimental group with different mean post-test and pre-test $(77.80-62.72)=15.08$. The increase was better than the control group with the mean difference between post-test and pre-test $(71.40-64.43)=6,97$.

\section{Acknowledgements}

The author would like to thank profusely all students who are willing to take the time, be directly involved, and participate in this research activity.

\section{REFERENCES}

[1] A. S. Lengkana, A. A. Rahman, M. N. Alif, G. Mulya, A. Priana, and D. B. Hermawan, "Static and Dynamic Balance Learning in Primary School Students," Int. J. Hum. Mov. Sport. Sci., vol. 8, no. 6, pp. 469-476, 2020. DOI: 10.13189/saj.2020.080620.

[2] B. Callary, S. Rathwell, and B. W. Young, "Coach Education and Learning Sources for Coaches of Masters Swimmers," Int. Sport Coach. J., vol. 5, no. 1, pp. 47-59, 2018.

[3] T. Muhtar, T. Supriyadi, A. S. Lengkana, and S. Hanifah, "Religious characters-based physical education learning in elementary school," Int. J. Learn. Teach. Educ. Res., vol. 18, no. 12, pp. 211-239, 2019.

[4] A. S. Lengkana, J. Tangkudung, and A. Asmawi, "The effectiveness of thigh lift exercises using rubber on the ability of acceleration on sprint runs," in Journal of Physics: Conference Series, 2019, vol. 1318, no. 1, p. 12031.

[5] A. A. Rahman and A. Angraeni, "Empowering learners with role-playing game for vocabulary mastery," Int. J. Learn. Teach. Educ. Res., vol. 19, no. 1, pp. 60-73, 2020.

[6] Rezki, R. Jatra, and N. Risma SM, “An analysis of freestyle swimming technique of university students of swimming course," pp. 258-265, 2019.

[7] E. Nikšić, E. Beganović, M. Joksimović, S. Nasrolahi, and I. DJoković, "The impact of strength and coordination on the success of performance of the freestyle swimming," Eur. J. Phys. Educ. Sport Sci., 2019.

[8] A. Suherman, E. Saptani, A. Setialengkana, and R. G. Nugraha, "Understanding the teaching style of physical education teacher in primary school through audio visual media," in Journal of Physics: Conference Series, 2019, vol. 1318 , no. 1, p. 12122.

[9] T. Muhtar, T. Supriyadi, and A. S. Lengkana, "Character Development-based Physical Education Learning Model in Primary School," vol. 8, no. 6, pp. 337-354, 2020.

[10] M. Giannousi, F. Mountaki, and E. Kioumourtzoglou, “The 
effects of verbal and visual feedback on performance and learning freestyle swimming in novice swimmers," Kinesiology, vol. 49, no. 1, 2017.

[11] M. A. M. Dos Santos et al., "The influence of anthropometric variables, body composition, propulsive force and maturation on $50 \mathrm{~m}$ freestyle swimming performance in junior swimmers: An allometric approach," J. Sports Sci., pp. 1-6, 2021.

[12] T. M. Barbosa et al., "Characterization of speed fluctuation and drag force in young swimmers: A gender comparison," Hum. Mov. Sci., vol. 32, no. 6, pp. 1214-1225, 2013.

[13] N. Vezos, V. Gourgoulis, N. Aggeloussis, P. Kasimatis, C. Christoforidis, and G. Mavromatis, "Underwater stroke kinematics during breathing and breath-holding front crawl swimming," J. Sport. Sci. Med., vol. 6, no. 1, pp. 58-62, 2007.

[14] D. Haller, Belajar Berenang. Bandung: PIONIR JAYA, 2011.

[15] A. F. Turdaliyevich and A. B. Pulatovna, "Organization of Swimming Lessons in Preschool Institutions," Am. J. Soc. Sci. Educ. Innov., vol. 2, no. 07, pp. 322-330, 2020.

[16] K. S. Morris, M. A. Osborne, M. E. Shephard, T. L. Skinner, and D. G. Jenkins, "Velocity, aerobic power and metabolic cost of whole body and arms only front crawl swimming at various stroke rates," Eur. J. Appl. Physiol., vol. 116, no. 5, pp. 1075-1085, 2016.

[17] S. M. Willcox-Pidgeon, A. E. Peden, and J. Scarr, "Exploring children's participation in commercial swimming lessons through the social determinants of health," Heal. Promot. J. Aust., 2020.

[18] M. Gaal, "Swim Training.," Swim Magazine, vol. 20, no. 3, pp. 12-14, 2004.

[19] G. Barclay, 50 SWIM TIPS For Junior and Age Group. 2012.

[20] M. L. Zampagni, D. Casino, P. Benelli, A. Visani, M. Marcacci, and G. De Vito, "Anthropometric and strength variables to predict freestyle performance times in elite master swimmers," J. Strength Cond. Res., vol. 22, no. 4, pp. 1298-1307, 2008.

[21] A. S. McCullough et al., "Factors affecting flutter kicking speed in women who are competitive and recreational swimmers," J. Strength Cond. Res., vol. 23, no. 7, pp. 2130-2136, 2009.

[22] P. G. Morouço, D. A. Marinho, M. Izquierdo, H. Neiva, and M. C. Marques, "Relative Contribution of Arms and Legs in 30 s Fully Tethered Front Crawl Swimming," Biomed Res. Int., vol. 2015, 2015.

[23] D. G. Thomas, Swimming Steps to Success. Champaign: Human Kinetics, 2005.

[24] J. Tangkudung and W. Puspitorini, Kepelatihan Olahraga Pembinaan Prestasi Olahraga, 2nd ed. Jakarta: Cerdas Jaya, 2012.

[25] Widiastuti and F. Hamamah, "Model Pembelajaran Renang (Fh) Bagi Siswa Prasekolah," JPUD - J. Pendidik. Usia Dini, vol. 11, no. 2, pp. 358-368, 2017.
[26] I. Akhmad, Dasar-Dasar Melatih Fisik Olahragawan. Medan: Unimed Press, 2013.

[27] Sutrisno and Suyadi, Desain Kurikulum Perguruan Tinggi. Bandung: PT Remaja Rosdakarya, 2016.

[28] M. Luebbers, "Swim Tether Stationary Swimming Belt," 2019. .

[29] K. B. Dos Santos, P. C. B. Bento, G. Pereira, C. Payton, and A. L. F. Rodacki, "Front crawl swimming performance and bi-lateral force asymmetry during land-based and tethered swimming tests," J. Sports Sci. Med., vol. 16, no. 4, p. 574, 2017.

[30] Sugiyono, Metode penelitian pendidikan:(pendekatan kuantitatif, kualitatif dan $R \& D)$. Alfabeta, 2008.

[31] A. Gomez-Bruton et al., "Factors affecting children and adolescents 50 meter performance in freestyle swimming.," J. Sports Med. Phys. Fitness, vol. 56, no. 12, pp. 1439-1447, 2015.

[32] E. A. A. Anto, S. Sugiyanto, and H. Liskustyawati, "Development of Video Modelling of Freestyle Swimming in High School Physical Education," Int. J. Multicult. Multireligious Underst., vol. 6, no. 1, pp. 332-345, 2019.

[33] A. S. Fadaei, "Comparing two results: Hake Gain and Dellow Gain, to analyze FCI data in active learning process," US-China Educ. Rev., vol. 9, no. 1, pp. 31-39, 2019.

[34] N. Nazurty, "Learning Strategies in Reading: The Case of Indonesian Language Education Student Teachers," Univers. J. Educ. Res. USA, vol. 7, no. 11, 2020.

[35] T. Ngoc and S. Samad, "A Qualitative Case Study into Exploring the Learning Styles and Learning Strategies of Non English Major Vietnamese College Students," Univers. J. Educ. Res., vol. 8, no. 1A, pp. 76-86, 2020.

[36] E. M. Dworak, W. Revelle, P. Doebler, and D. M. Condon, "Using the International Cognitive Ability Resource as an open source tool to explore individual differences in cognitive ability," Pers. Individ. Dif., vol. 169, p. 109906, 2021.

[37] P. Kyllonen and R. Thomas, "Using response time for measuring cognitive ability illustrated with medical diagnostic reasoning tasks," in Integrating timing considerations to improve testing practices, Routledge, 2020, pp. 122-141.

[38] Y.-C. Chen, F.-Y. Yang, and C.-C. Chang, "Conceptualizing Spatial Abilities and Their Relation to Science Learning from a Cognitive Perspective.," J. Balt. Sci. Educ., vol. 19, no. 1, pp. 50-63, 2020.

[39] R. Gray and A. J. Gow, "How is musical activity associated with cognitive ability in later life?," Aging, Neuropsychol. Cogn., vol. 27, no. 4, pp. 617-635, 2020.

[40] B. Wilson et al., "Non-adjacent dependency learning in humans and other animals," Top. Cogn. Sci., vol. 12, no. 3, pp. 843-858, 2020.

[41] M. Strzala, A. Stanula, P. Krezalek, A. Ostrowski, M. Kaca, and G. Glab, "Influence of morphology and strength on front crawl swimming speed in junior and youth age-group swimmers," J. Strength $\backslash \&$ Cond. Res., vol. 33, no. 10, pp. 2836-2845, 2019. 
[42] K. Narita, M. Nakashima, and H. Takagi, "Developing a methodology for estimating the drag in front-crawl swimming at various velocities," J. Biomech., vol. 54, pp. $123-128,2017$.

[43] Z. B. Aktug, R. Iri, and E. Top, "The Investigation of the Relationship between Children's 50m Freestyle Swimming Performances and Motor Performances.," Asian J. Educ. Train., vol. 4, no. 1, pp. 41-44, 2018.

[44] T. Li et al., "Highly efficient freestyle magnetic nanoswimmer," Nano Lett., vol. 17, no. 8, pp. 5092-5098, 2017.

[45] E. Nicol, K. Ball, and E. Tor, "The biomechanics of freestyle and butterfly turn technique in elite swimmers," Sport. Biomech., 2019.

[46] M. Köroglu and K. Yigiter, "Effects of Swimming Training on Stress Levels of the Students Aged 11-13.," Univers. $J$. Educ. Res., vol. 4, no. 8, pp. 1881-1884, 2016.

[47] E. A. Raspopova and I. V Chebotareva, "Sexual dimorphism in young 11-12 year-old divers and swimmers," Педагогико-психологические и медико-биологические проблемы физической культуры и спорта, vol. 15, no. 1 (eng), 2020.

[48] E. S. Walsted et al., "Laryngoscopy during swimming: a novel diagnostic technique to characterize swimming-induced laryngeal obstruction," Laryngoscope, vol. 127, no. 10, pp. 2298-2301, 2017.

[49] D. B. Pyne and R. L. Sharp, "Physical and energy requirements of competitive swimming events," Int. J. Sport Nutr. Exerc. Metab., vol. 24, no. 4, pp. 351-359, 2014. 